\title{
High sensitivity detection of Plasmodium species reveals positive correlations between infections of different species, shifts in age distribution and reduced local variation in Papua New Guinea Ivo Mueller*1, Simone Widmer ${ }^{2}$, Daniela Michel ${ }^{2}$, Seri Maraga1, David T McNamara ${ }^{3}$, Benson Kiniboro ${ }^{1}$, Albert Sie ${ }^{1}$, Thomas A Smith ${ }^{2}$ and Peter A Zimmerman*3
}

Address: ${ }^{1}$ Papua New Guinea Institute of Medical Research, Goroka, PO Box 60, EHP 441, Papua New Guinea, ${ }^{2}$ Swiss Tropical Institute, Department of Medical Parasitology and Infection Biology, and Department of Public Health and Epidemiology, Socinstrasse 57, PO Box, CH4002 Basel, Switzerland and ${ }^{3}$ Center for Global Health \& Diseases, Case Western Reserve University, School of Medicine, Wolstein Research Building, 10900 Euclid Avenue, Cleveland, Ohio, 44106-7286, USA

Email: Ivo Mueller* - ivomueller@fastmail.fm; Simone Widmer - simone-1.widmer@novartis.com; Daniela Michel - danemichel@bluewin.ch; Seri Maraga - serimaraga@gmail.com; David T McNamara - dtm2@case.edu; Benson Kiniboro - imrbenson@yahoo.com.au; Albert Sie - Albert.Sie@pngimr.org.pg; Thomas A Smith - thomas-a.smith@unibas.ch; Peter A Zimmerman* - paz@case.edu

* Corresponding authors

Published: II March 2009

Malaria Journal 2009, 8:4I doi:|0.1|186/1475-2875-8-4|
Received: 14 April 2008

Accepted: II March 2009

This article is available from: http://www.malariajournal.com/content/8/I/4I

(C) 2009 Mueller et al; licensee BioMed Central Ltd.

This is an Open Access article distributed under the terms of the Creative Commons Attribution License (http://creativecommons.org/licenses/by/2.0), which permits unrestricted use, distribution, and reproduction in any medium, provided the original work is properly cited.

\begin{abstract}
Background: When diagnosed by standard light microscopy (LM), malaria prevalence can vary significantly between sites, even at local scale, and mixed species infections are consistently less common than expect in areas co-endemic for Plasmodium falciparum, Plasmodium vivax and Plasmodium malariae. The development of a high-throughput molecular species diagnostic assay now enables routine PCR-based surveillance of malaria infections in large field and intervention studies, and improves resolution of species distribution within and between communities.

Methods: This study reports differences in the prevalence of infections with all four human malarial species and of mixed infections as diagnosed by LM and post-PCR ligase detection reaction - fluorescent microsphere (LDR-FMA) assay in I 5 villages in the central Sepik area of Papua New Guinea.

Results: Significantly higher rates of infection by $P$. falciparum, $P$. vivax, $P$. malariae and Plasmodium ovale were observed in LDRFMA compared to LM diagnosis $(P<0.00 I)$. Increases were particularly pronounced for $P$. malariae $(3.9 \%$ vs $13.4 \%)$ and $P$. ovale $(0.0 \%$ vs $4.8 \%)$. In contrast to LM diagnosis, which suggested a significant deficit of mixed species infections, a significant excess of mixed infections over expectation was detected by LDR-FMA $(p<0.00 \mathrm{I})$. Age of peak prevalence shifted to older age groups in LDR-FMA diagnosed infections for P. falciparum (LM: 7-9 yrs 47.5\%, LDR-FMA: 10-19 yrs 74.2\%) and P. vivax (LM: 4-6 yrs 24.2\%, LDR-FMA: 7-9 yrs 50.9\%) but not P. malariae infections (I0-19 yrs, LM: 7.7\% LDR-FMA: 2I.6\%). Significant geographical variation in prevalence was found for all species (except for LM-diagnosed $P$. falciparum), with the extent of this variation greater in LDR-FMA than LM diagnosed infections (overall, $84.4 \%$ vs. $37.6 \%$ ). Insecticide-treated bednet (ITN) coverage was also the dominant factor linked to geographical differences in Plasmodium species infection prevalence explaining between $60.6 \%-74.5 \%$ of this variation for LDR-FMA and $81.8 \%-90.0 \%$ for LM (except $P$. falciparum), respectively.
\end{abstract}

Conclusion: The present study demonstrates that application of molecular diagnosis reveals patterns of malaria risk that are significantly different from those obtained by standard LM. Results provide insight relevant to design of malaria control and eradication strategies. 


\section{Introduction}

Malaria is an infectious disease that shows considerable spatial heterogeneity on global [1,2], regional [3-6] and local scales [7-10]. While it has been possible at some levels of resolution to relate variation in prevalence or incidence of infections with differences in environment and measures of transmission potential (such as entomological inoculation rates) on global and regional levels $[4,6,11]$, it has been difficult to evaluate Plasmodium species prevalence and determine the causes of the often pronounced local heterogeneity in malarial prevalence [12].

As all human Plasmodium species share both host and vector, mixed species infections are commonly observed. An extensive review of the literature on mixed species malaria infections by Ritchie [13] concluded that there are geographic differences in the way that human malaria species interact and that these interactions may even change from year to year for a given location. In selected field surveys from areas with a Plasmodium falciparum, Plasmodium malariae and Plasmodium vivax mix, a deficit of mixed infections has generally been recorded [14,15], suggesting heterologous suppression between those parasite species. In contrast, a surplus of mixed infections has been observed in areas with P. falciparum, P. malariae and Plasmodium ovale $[14,15]$. However, there is generally great variability in results between studies and it cannot be ruled out that observed fluctuations in the frequency of mixed infections may be due to limitations in the sensitivity of light microscopic (LM) species identification [16]. More recent studies using PCR techniques found much higher levels of mixed infections [17] and random distribution of different infections $[18,19]$. Earlier studies of mixed infections in mostly asymptomatic people during cross-sectional surveys has not provided conclusive evidence for interactions between the different Plasmodium species.

Previous studies on spatial patterns of malarial infections were based exclusively on light microscopy diagnosis (LM) of infection, which has a significantly lower sensitivity for detecting malarial infections compared to PCRbased diagnostic assays $[17,20]$. The more limited sensitivity is a particular problem in areas such as Papua New Guinea (PNG) where four human malaria species are endemic ( $P$. falciparum, P. vivax, P. malariae and P. ovale), and mixed species infections are very common [21]. In these circumstances LM has been observed to be particularly poor in detecting the less common $P$. malariae and $P$. ovale infections [22] as well as for accurate diagnosis of mixed species infections [16].

The developments of a high-throughput post-PCR, LDRFMA species typing assay [23] now makes feasible the routine molecular diagnosis of malaria infections in large field and intervention studies. This assay evaluates $P$. falciparum, $P$. vivax, $P$. malariae and $P$. ovale simultaneously and is performed in 96-well plate format to ensure efficient sample processing. Overall high specificity and sensitivity of the assay provides more accurate assessment of minority species in mixed infections. In addition, good correlations between parasite density and median fluorescence intensity confirmed that the assay is semi-quantitative $[23,24]$. In a recent comparison of malarial age groupbased infection patterns detected by LM vs LDR-FMA methods in samples of over 1000 people (all ages), an increase in the prevalence of non-falciparum compared to falciparum infections, and a significant shift in distribution of infections to older age groups by LDR-FMA compared to LM diagnosis was observed [24]. Moreover, we found that adolescents and adults very commonly harbour submicroscopic malarial infections. Similarly, in a cohort of children 5-14 years we found a significantly lower incidence of new $P$. vivax compared to $P$. falciparum blood stage infections when diagnosed by LM but identical rates when PCR diagnosis was used [25].

It is, therefore, becoming clear that increased application of PCR-diagnosis significantly alters the understanding of the epidemiology of different Plasmodium species. In order to further evaluate the effect of the increased sensitivity of detection on patterns of Plasmodium species infection, here LM and LDR-FMA diagnostic methods were compared in a series of 15 cross-sectional population surveys at five distinct locations in the central Sepik region of East Sepik province, PNG.

\section{Methods \\ Study site and design}

The selected study sites in the Maprik and Wosera-Gawi districts cover a combined area of over $160 \mathrm{~km}^{2}$ that is characterized by low hills, plains and riverine plains with a wet tropical climate [26]. The natural vegetation is lowland hill forest that has mostly been replaced by re-growth following cultivation. Extensive grasslands are common on the riverine plans near the Sepik River. The Wosera study site described previously [26] is situated near the center of this expanded study region. In the early 1990's malaria was found to be holoendemic with a peak prevalence of $77 \%$ in children 5-9 years of age in the central Wosera area [26], with entomological inoculation rates (EIR) estimated at 35.4 infective bites/person-year for $P$. falciparum, 12.1 for $P$. vivax, and 9.6 for $P$. malariae [27]. By comparison, recent human studies in the Wosera found prevalence of $P$. falciparum to be significantly reduced [24].

For the present study five distinct areas surrounding local health facilities (i.e. Brukham, Burui, Ilaita, Ulupu and Wombisa HC) were selected (Figure 1). Brukham, Ilaita 


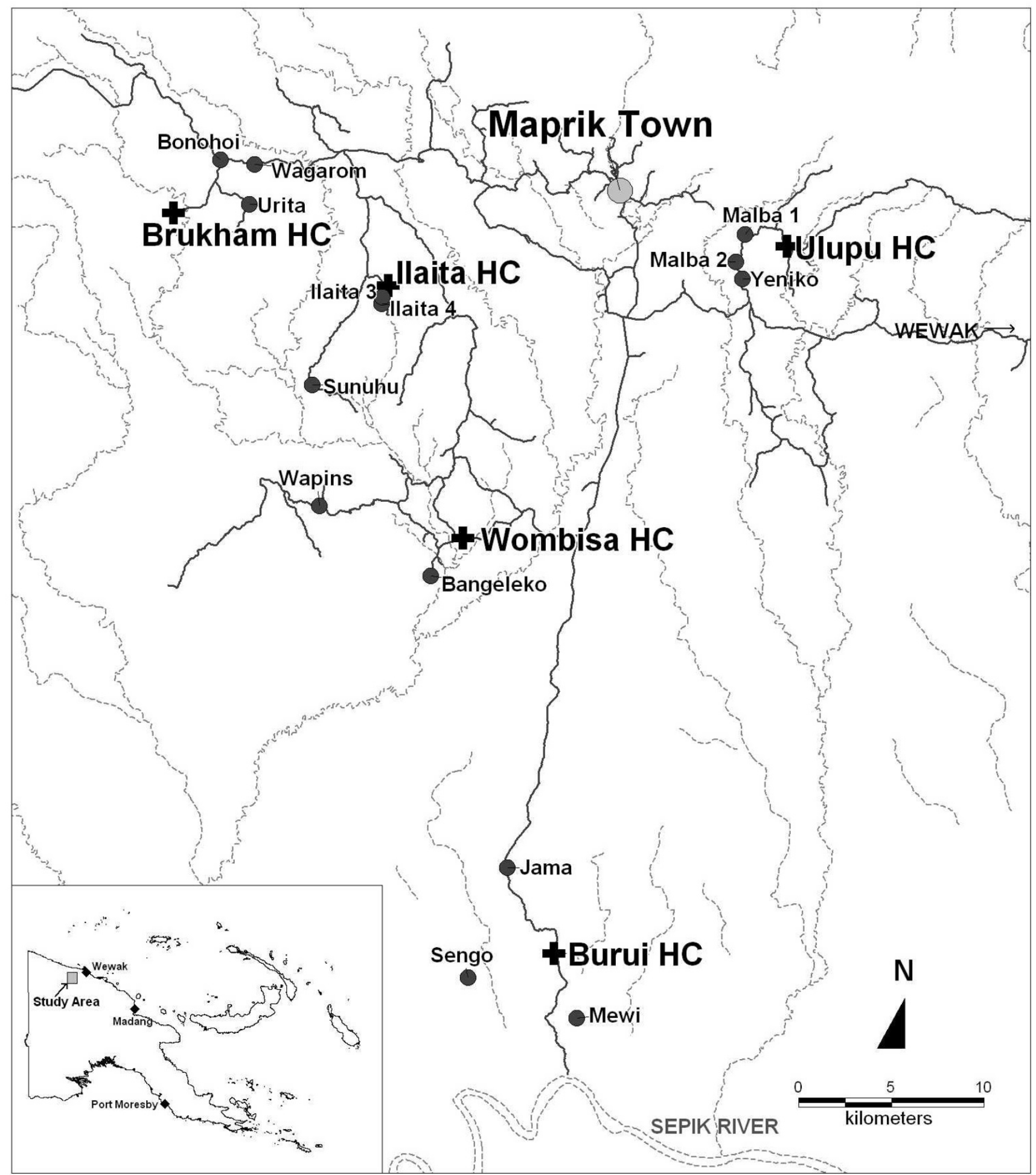

Figure I

Locations of cross-sectional surveys in vicinity of 5 health centres (HC) in the Middle Sepik Region of Papua New Guinea. Wombisa village and health centre are in the same location. 
and Ulupu are situated in the foothills of the Prince Alexander range, Burui and Wombisa are in the Sepik River plain. In April and May 2005, 3 villages were surveyed in each of the five areas. In order to achieve a near-random sample of the village population a household-based sampling strategy was pursued. A number of households with a total population of $150-200$ persons were included in each survey. The surveys included every member of the selected households who could be reached on the day of survey. Individual informed consent was obtained from all study participants (or consent granted by parents or guardians for inclusion of children) using study protocols evaluated and approved by the PNG Medical Research Advisory Committee (MRAC 00.26 \& MRAC 05.20).

From each household a semi-structured questionnaire was administered to collect data on type of house, household assets, education of the parents, personal use of bednets, recent health facility attendance and use of antimalarial drugs. From each individual, a thick and thin film was prepared on a single slide and a $250 \mu \mathrm{l}$ blood sample collected into a K+EDTA microtainer from a finger or heel prick. Haemoglobin measurements were made from this blood sample using a HemoCue 201+ Hb meter (Angholm, Sweden); remaining blood was preserved for extraction of DNA.

A socio-economic index was created using data on household ownership of consumer durables (i.e. bed, mattress, bednet, chairs, umbrella, clothing cupboard, kerosene pressure lamp, kerosene cooker, electric torch, radio, television, car). Households that owned $<$ five consumer durables were classified as "low", > five consumer durables were classified as "medium", those with $>10$ as "high" socio-economic status.

\section{Blood smear preparation and examination}

All smears were stained with $2.5 \%$ buffered Giemsa (pH 7.2) for 35 minutes and examined by LM. Slides were declared negative if no parasites were seen in 100 thick film fields. The parasite species in positive films were identified and densities were recorded as the number of parasites/200 WBC. Densities were calculated assuming $8,000 \mathrm{WBC} / \mu \mathrm{l}[26]$. Sexual and asexual stage parasite densities were reported separately for $P$. falciparum only. All slides with densities less than $200 / \mu \mathrm{l}$, along with a randomly selected $20 \%$ of all blood films were routinely reexamined. If less than $80 \%$ concordance was achieved between LM evaluations, the entire batch of slides was reread.

\section{DNA extraction and molecular diagnostic assay}

Parasite DNA was extracted from the cell pellets using QIAmp 96 DNA Blood kits (Qiagen, CA).
A semi-quantitative post-PCR, ligase detection reaction/ fluorescent microsphere assay (LDR-FMA) [23] was used to determine the presence of infection by $P$. falciparum, $P$. vivax, $P$. malariae and $P$. ovale. The design and sensitivity of this assay has been described previously [23,24,28]. In short, this assay combines PCR amplification of the $18 \mathrm{~S}$ ribosomal RNA gene (491-500 bp fragments) using genus specific primers, followed by a multiplex speciesspecific ligation detection reaction (LDR). The LDR products are hybridized to Luminex ${ }^{\circledast}$ FlexMAP ${ }^{\mathrm{Tm}}$ "classification" bead sets (5'), and receive "reporter" labelling following incubation with streptavidin-R-phycoerythrin that binds to biotin (3'). Doubly labelled species-specific LDR complexes are detected using a Bio-Plex array reader (Bio-Rad Laboratories, Hercules, CA). Species-specific fluorescence data were collected by Bio-Rad software, Bio-Plex Manager 3.0 (Bio-Rad Laboratories, Hercules, CA). In order to guarantee maximum sensitivity for the detection of Plasmodium infections the PCR-cycle number was set at 35 . Differentiation of negative from positive fluorescent signals was performed by comparing median fluorescent intensity (MFI) from study participants against values obtained from two negative controls on each 96-well plate. Cut-off values for positivity were set at the two standard deviations above the mean MFI of negative controls.

\section{Data analysis}

Differences in prevalence of malarial infections among villages and areas and univariate association between categorical explanatory variables were tested using $\chi^{2}$ test, multivariate predictors of infection risk were determined using logistic regression. Non-parametric Spearman's correlations were used to compare parasite density by light microscopy and mean fluorescence intensities, while parametric correlations were calculated for the association of prevalence of infection and mean haemoglobin at village level.

Within and between village variance in risk of malarial infections were estimated using a hierarchical Bayesian logistic model, i.e.

$\mathrm{r}_{\mathrm{i}} \sim \operatorname{Bernoulli}\left(\mathrm{p}_{\mathrm{i}}\right)$

where $\operatorname{logit}\left(\mathrm{p}_{\mathrm{i}}\right)=\beta_{\mathrm{a}(\mathrm{i})}+\sigma_{\mathrm{j}(\mathrm{i})}+\theta_{\mathrm{j}(\mathrm{i}) \mathrm{k}(\mathrm{i})}$.

and " $i$ " indexes the individuals, "a" the age-groups, " $j$ " the area and " $k$ " the village within area. " $r_{i}$ " indicates whether individual " $\mathrm{i}$ " is infected with a given Plasmodium species, " $\mathrm{p}_{\mathrm{i}}$ " denotes expected value, " $\beta_{\mathrm{a}(\mathrm{i})}$ " is a fixed effect for the age group, " $\sigma_{\mathrm{j}(\mathrm{i})}$ " is a random effect for the area and the " $\theta_{\mathrm{j}(\mathrm{i}) \mathrm{k}(\mathrm{i})} "$ is a random effect term for the village. In the models adjusting for bednet coverage, an additional linear effect is introduced into the model. All models were 
fitted using WinBugs 1.4 [29] assuming normal priors, with the distributions of the random effects centred on zero.

Variance components were estimated for all species with and without adjusting for bednet coverage. The relative contribution of between-area variance was determined by dividing the area variance component with the total spatially structure variance, i.e $\sigma_{\mathrm{i}(\mathrm{i})} /\left(\sigma_{\mathrm{i}(\mathrm{i})+} \theta_{\mathrm{j}(\mathrm{i}) \mathrm{k}(\mathrm{i})}\right)$. The effect of difference in bednet coverage on spatially structured variance was determined by comparing the individual variance component from models with and without inclusion of the bednet covariate. Variance components, their relative sizes, and changes following adjustment for bednet coverage are all reported on a logit scale.

\section{Results}

A total of 2,744 volunteers from 15 villages in five distinct geographical areas (Figure 1) participated in the cross-sectional surveys. Of these $121(4.4 \%)$ were excluded because of lacking demographic or LM data, while insufficient finger-prick blood sample for LDR-FMA analysis led to exclusion of an additional 96 (3.5\%) individuals. Over- all 2,527 participants from 659 households with completed demographic information (median participation per household: 4, range (1-17)) were available for study. Of these 1,331 (52.7\%) were female, 982 (38.9\%) children $<10$ yrs and $1,189(47.1 \%)$ adults $>=20 \mathrm{yrs}$ of age.

In this population, $1,121(44.4 \%)$ and $1,844(73.0 \%)$ participants had LM and LDR-FMA detectable Plasmodium species infections, respectively (Table 1). Diagnosis of infections by LM and LDR-FMA were highly significantly associated $\left(\mathrm{X}^{2}>=493.6, \mathrm{p}<0.001\right)$ for all species except $P$. ovale which is rarely detected by LM in PNG [22]. While the higher sensitivity of the LDR-FMA assay is reflected in a large number of infections that were only detected by this assay (P. falciparum: 667, P. vivax 561, P. malariae 251, $P$. ovale 121), very few LM-positive infections were not detected by the LDR-FMA assay ( $P$. falciparum: 46, P. vivax 28, P. malariae: $12, P$. ovale: 0$)$. Fluorescence intensities of samples that were positive by both LM and LDR-FMA were significantly higher than those that were only LDRFMA positive $(P$. falciparum: 11,963 vs 4,$970 ; P$. vivax: 10,718 vs 5,109 ; P. malariae: 10,630 vs 6,422 ; all t-tests $p$ $<0.001$ ). For infections positive by both methods, fluo-

Table I: Prevalence of malarial infections (as diagnosed by LM and LDR-FMA assay) in study communities.

\begin{tabular}{|c|c|c|c|c|c|c|c|c|c|c|c|c|}
\hline \multirow[b]{2}{*}{ Area } & \multirow[b]{2}{*}{ Village } & \multirow[b]{2}{*}{$\mathbf{N}$} & \multicolumn{5}{|c|}{ Light microscope } & \multicolumn{5}{|c|}{ LDR - FMA } \\
\hline & & & $\begin{array}{l}\mathbf{P f} \\
\%\end{array}$ & $\begin{array}{l}\mathbf{P v} \\
\%\end{array}$ & $\begin{array}{c}\mathbf{P m} \\
\%\end{array}$ & $\begin{array}{c}\text { Po } \\
\%\end{array}$ & $\begin{array}{l}\text { All } \\
\%\end{array}$ & $\begin{array}{l}\text { Pf } \\
\%\end{array}$ & $\begin{array}{l}\mathbf{P v} \\
\%\end{array}$ & $\begin{array}{c}\text { Pm } \\
\%\end{array}$ & $\begin{array}{c}\text { Po } \\
\%\end{array}$ & $\begin{array}{c}\text { All } \\
\%\end{array}$ \\
\hline \multirow[t]{4}{*}{ Burui } & & 489 & 26.8 & 9.0 & 1.8 & 0.0 & 36.1 & 43.4 & 28.4 & 4.7 & 3.1 & 63.2 \\
\hline & Jama & 203 & 22.2 & 8.9 & 1.0 & 0.0 & 32.0 & 35.0 & 27.6 & 2.5 & 3.4 & 59.1 \\
\hline & Sengo & 153 & 29.4 & 7.2 & 3.3 & 0.0 & 38.6 & 49.7 & 22.9 & 6.5 & 3.9 & 62.8 \\
\hline & Mewi & 133 & 30.8 & 11.3 & 1.5 & 0.0 & $4 I .4$ & 48.9 & 36.1 & 6.0 & 1.5 & 69.9 \\
\hline \multirow[t]{4}{*}{ Wombisa } & & 491 & 29.7 & 10.8 & 2.0 & 0.0 & 40.5 & 53.8 & 32.4 & $I I .4$ & 3.1 & 72.7 \\
\hline & Wapins & 145 & 21.4 & 11.0 & 2.8 & 0.0 & 34.5 & 49.7 & 29.0 & 8.3 & 4.1 & 69.7 \\
\hline & Bangeleko & 172 & 33.7 & 6.4 & 1.2 & 0.0 & 39.5 & 58.7 & 32.6 & 14.5 & 1.2 & 76.7 \\
\hline & Wombisa & 174 & 32.8 & 14.9 & 2.3 & 0.0 & 46.6 & 52.3 & 35.1 & 10.9 & 4.0 & 71.3 \\
\hline \multirow[t]{4}{*}{ Ulupu } & & 521 & 28.4 & I7.I & 2.5 & 0.0 & 43.7 & 52.2 & 39.9 & 10.0 & 4.8 & 72.6 \\
\hline & Malba I & 163 & 23.3 & 14.7 & 0.6 & 0.0 & 36.8 & 50.3 & 43.6 & 9.2 & 3.1 & 76.1 \\
\hline & Malba 2 & 174 & 28.2 & 23.0 & 5.7 & 0.0 & 50.0 & 58.6 & 40.8 & 14.4 & 6.3 & 74.1 \\
\hline & Yeniko & 184 & 33.2 & 13.6 & I.I & 0.0 & 44.0 & 47.8 & 35.9 & 6.5 & 4.9 & 67.9 \\
\hline \multirow[t]{4}{*}{ Brukham } & & 515 & 35.0 & 15.9 & 4.5 & 0.0 & 47.8 & 60.8 & 39.8 & I8.I & 6.6 & 77.3 \\
\hline & Urita & 166 & 28.9 & 18.7 & 3.6 & 0.0 & 41.6 & 60.8 & 45.2 & 17.5 & 6.6 & 78.3 \\
\hline & Bonohoi & 174 & 32.8 & 8.6 & 4.6 & 0.0 & 41.4 & 54.6 & 33.9 & 16.1 & 6.3 & 71.8 \\
\hline & Wagarom & 175 & 42.9 & 20.6 & 5.1 & 0.0 & 60.0 & 66.9 & 40.6 & 20.6 & 6.9 & 81.7 \\
\hline \multirow[t]{4}{*}{ Ilaita } & & 511 & 30.0 & 19.6 & 8.6 & 0.0 & 52.6 & 63.8 & 37.2 & 22.3 & 6.3 & 78.7 \\
\hline & Sunuhu & 188 & 45.2 & 14.9 & 15.4 & 0.0 & 67.6 & 78.7 & 38.8 & 30.9 & 9.0 & 85.7 \\
\hline & Ilaita 3 & 148 & 15.5 & 18.9 & 4.1 & 0.0 & 36.5 & 56.1 & 35.8 & 14.2 & 3.4 & 75.7 \\
\hline & llaita 4 & 175 & 24.6 & 25.1 & 5.1 & 0.0 & 50.3 & 54.3 & 36.6 & 20.0 & 5.7 & 73.7 \\
\hline Overall & & 2,527 & 29.90 & 14.60 & 3.90 & 0.00 & 44.4 & 54.90 & 35.70 & 13.40 & 4.80 & 4.80 \\
\hline
\end{tabular}

$\mathrm{Pf}=P$. falciparum, $\mathrm{Pv}=\mathrm{P}$. vivax, $\mathrm{Pm}=\mathrm{P}$. malariae, $\mathrm{Po}=\mathrm{P}$. ovale 
rescence intensities were significantly correlated with densities by LM for P. falciparum ( $\mathrm{rho}=0.51, \mathrm{p}<0.001$ ) and P. vivax ( $\mathrm{rho}=0.41, \mathrm{p}<0.001$ ) but not for P. malariae (rho $=-0.05, \mathrm{p}=0.67)$.

By LM, $P$. falciparum was the most common parasite with a prevalence of $29.9 \%(756 / 2,527)$ followed by $P$. vivax and $P$. malariae with a prevalence of $14.6 \%(368 / 2,527)$ and $3.9 \%(99 / 2,527)$, respectively (Table 1$)$. No infections with $P$. ovale were detected by LM. Plasmodium infections were most frequent in the 7-9, and 4-6 year-old children (67.2\%, $\mathrm{CL}_{95}: 61.2-72.8$ and; $60.4 \%, \mathrm{CL}_{95}$ : 54.9-65.8) respectively, followed by adolescents (10-19 years: $55.9 \%, \mathrm{CL}_{95}$ : 50.6-61.1), $2-3$ year olds $(54.7 \%$, $\left.\mathrm{CL}_{95}: 47.7-61.5\right)$, adults (20-39 years: $33.9 \%, \mathrm{CL}_{95}: 30.5-$ $37.4,>=40$ years: $\left.\left.29.7, \mathrm{CL}_{95}: 25.5-34.3\right)\right)$ and infants $(0-$ 1 years: $\left.26.4 \%, \mathrm{CL}_{95}: 20.1-33.4\right)$. P. vivax reached peak prevalence in younger children (Figure 2: 4-6 years: 24.2\%, $\left.\mathrm{C}_{95}: 22.1-26.3\right)$ than P. falciparum (7-9 years: $47.5 \%$, $\left.\mathrm{CL}_{95}: 41.1-53.7\right)$ or P. malariae (10-19 years: $\left.7.7 \%, \mathrm{CL}_{95}: 3.7-8.8\right)$.

A significantly higher proportion of individuals were positive for infection when diagnosed by LDR-FMA (Table 1). This was the case for all species but was most pronounced for the less common species; $P$. falciparum prevalence increased 1.8 fold $(29.9 \%$ to $54.9 \%$, p $<0.001), P$. vivax 2.4 -fold ( $14.6 \%$ to $35.7 \%, \mathrm{p}<0.001)$ and P. malariae 3.4 fold $(3.9 \%$ to $13.4 \%, \mathrm{p}<0.001)$, while $P$. ovale was detected in samples from $4.8 \%(\mathrm{p}<0.001)$ of all participants. In parallel with these increases from LM to LDRFMA, more mixed infections were detected (Table 2, 4.0\% to $28.6 \%, \mathrm{p}<0.001$ ) and mixed infections were detected in a greater proportion of the infected samples $(9.0 \%$ to $39.2 \%, \mathrm{p}<0.001)$.

As in earlier studies $[18,19,24]$, we used the multiple-kind lottery model to determine whether there was a random distribution of Plasmodium species in the survey population (Table 2). Among both LM and LDR-FMA diagnosed infections a significant departure from random distribution was observed, albeit in different ways. By LM diagnosis single species infections were observed at significantly higher frequencies than expected, and different mixed Plasmodium species infections were observed at frequencies that were equal to, or lower than the expected frequencies. Overall, mixed infections were found in only $4.0 \%$ of all samples compared with the expected $5.8 \%$ (p $<0.001)$. Fewer mixed species infections were observed in Burui and Wombisa compared to the other areas (Additional files 1 \&2). In a given individual, infection with one species was negatively associated with the presence of any other species (Table 3). By LDR-FMA diagnosis, single and double species infections were observed at frequencies equal to or less than expected, whereas triple and quadru- ple infection assemblages (Table 1: $6.5 \%$ vs $3.8 \%$, p < $0.001)$ and negative samples $(27.0 \%$ vs $23.9 \%, \mathrm{p}=0.002)$ were significantly more common than expected. Among LDR-FMA diagnosed infections, however, positive associations were observed for all species pairs except $P$. falciparum/P. vivax (Table 3 ) in any given individual. While the general trend of negative associations between species in LM, and positive associations in LDR-FMA diagnoses are consistent across different age groups, the effects tended to be more pronounced in adults and adolescents (> $10 \mathrm{yrs}$ ) compared to children, except for LDR-FMA diagnosed $P$. falciparum, $P$. malariae and $P$. ovale which show a stronger association in children (Table 3 ).

For all Plasmodium species, the increase in apparent prevalence of infections detected by the LDR-FMA assay was proportionally larger in adults than in children (Figure 2). As a consequence the prevalence of infection appeared to peak at a later age for LDR-FMA-detectable infections than when diagnosis was performed by LM (Figure 2). Prevalence of infections peaked in adolescents $(10-19$ years: $P$. falciparum: $74.2 \%, \mathrm{CL}_{95}$ : 69.3-78.6; P. malariae: $21.6 \%$, $\mathrm{CL}_{95}$ : 17.5-26.3; P. ovale: 7.0\%, $\mathrm{CL}_{95}: 4.6-10.2$; mixed infections: $43.0 \%, \mathrm{CL}_{95}: 37.9-48.3$ ) in all species except $P$. vivax, where infections were most commonly found in children 7-9 years of age $\left(50.9 \%, \mathrm{CL}_{95}: 44.8-57.1\right)$.

The risk of infections with malaria parasites was independently associated with a number of risk factors. The most important predictors were coverage of insecticide treated ITNs, educational level of the female household head and socio-economic status of family (Table 4). ITN coverage was significantly associated with a reduction in risk of infection with all different malaria species both by LM and LDR-FMA, although for $P$. vivax a decrease was only observed at high ITN coverage (>90\%). People living in households where the mother spoke English or had attended at least 3 years of schooling also had a significantly lower risk of being infected with $P$. falciparum, $P$. vivax (LDR-FMA diagnosed only) and $P$. malariae infections but not with $P$. ovale. Only risk of infection with $P$. falciparum was significantly reduced in households of higher socio-economic status, while difference in house construction was only associated with difference in risk of LDR-FMA diagnosed $P$. falciparum and $P$. malariae infection.

For all species and both diagnostic methods, there were significant differences in prevalence of Plasmodium species infections among villages (Table $1, \mathrm{p}<0.001$ for all species, except $P$. ovale (LDR-FMA) $\mathrm{p}=0.03$ ), and areas $(\mathrm{p}<$ 0.001 for all species, except $P$. falciparum (LM) $\mathrm{p}=0.06$ ) and $P$. ovale (LDR-FMA) $\mathrm{p}=0.01$ ). By LM, infection prevalence for individual villages varied between $15.5 \%$ to $45.2 \%$ for $P$. falciparum (coefficient of variance (CV): 

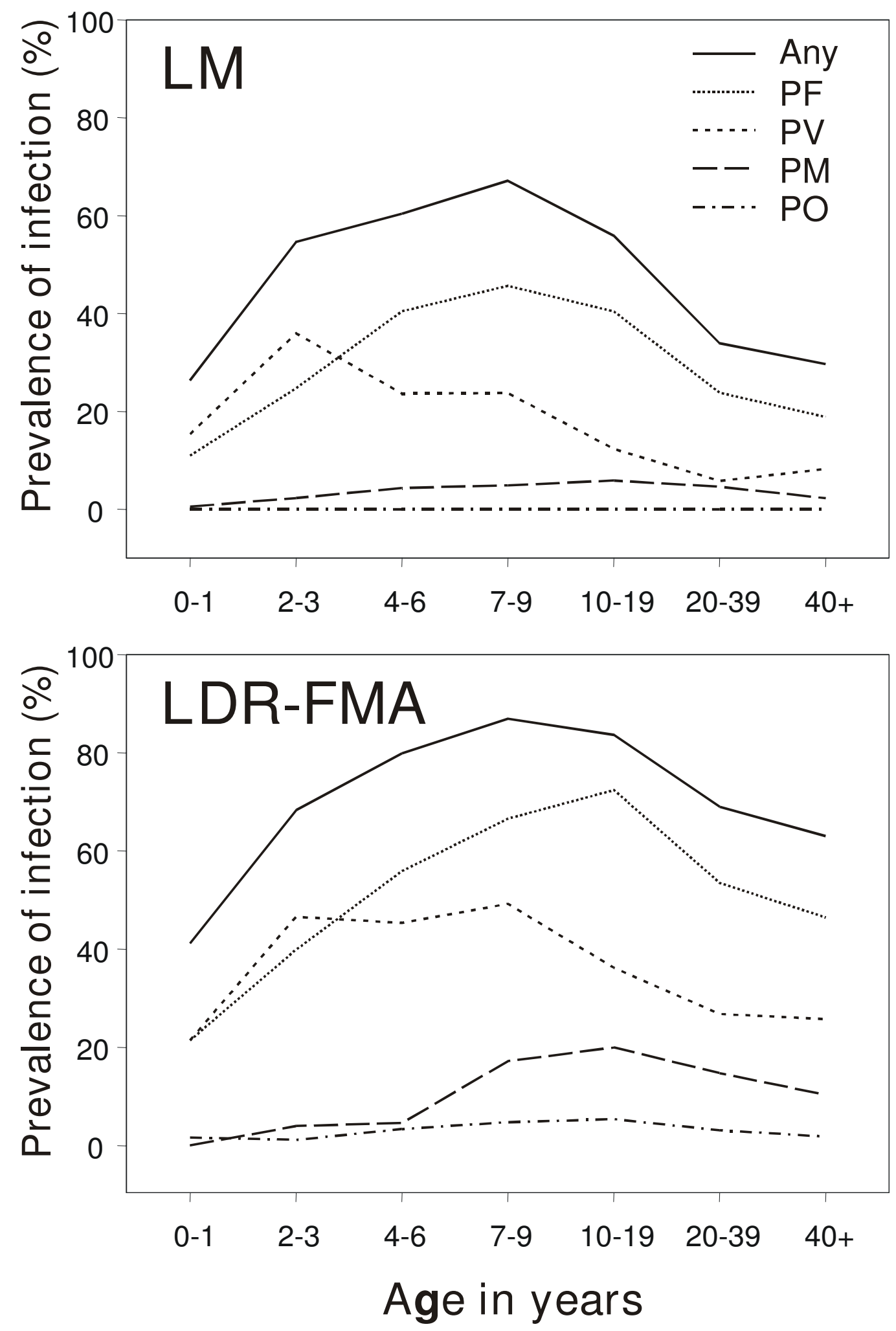

Figure 2

Age specific prevalence rates of malarial infections as diagnoses by light microscopy (LM) and LDR-FMA. 
Table 2: Comparison of observed and expected Plasmodium species assemblages by different diagnostic techniques.

\begin{tabular}{|c|c|c|c|c|c|c|}
\hline & \multicolumn{3}{|c|}{ Light microscopy } & \multicolumn{3}{|c|}{ LDR-FMA } \\
\hline & Observed & Expected ${ }^{\prime}$ & $\mathbf{x}^{2}$ & Observed & Expected & $\mathbf{X}^{2}$ \\
\hline neg & 1406 & 1453.2 & 1.5 & 683 & 605.0 & 10.1 \\
\hline $\mathrm{Pf}$ & 660 & 620.4 & 2.5 & 704 & 736.1 & 1.4 \\
\hline $\mathrm{Pv}$ & 276 & 247.7 & 3.2 & 350 & 335.2 & 0.6 \\
\hline $\mathrm{Pm}$ & 84 & 59.3 & 10.3 & 45 & 93.4 & 25.1 \\
\hline Po & 0 & 0.6 & 0.6 & 22 & 30.4 & 2.3 \\
\hline $\mathrm{Pf}+\mathrm{Pv}$ & 86 & 105.7 & 3.7 & 363 & 407.9 & 4.9 \\
\hline $\mathrm{Pf}+\mathrm{Pm}$ & 9 & 25.3 & 10.5 & 136 & 113.7 & 4.4 \\
\hline $\mathrm{Pf}+\mathrm{Po}$ & 0 & 0.2 & 0.2 & 27 & 37.0 & 2.7 \\
\hline $\mathrm{Pv}+\mathrm{Pm}$ & 5 & 10.1 & 2.6 & 26 & 51.8 & 12.8 \\
\hline $\mathrm{Pv}+\mathrm{Po}$ & 0 & 0.1 & 0.1 & 7 & 16.9 & 5.8 \\
\hline $\mathrm{Pm}+\mathrm{Po}$ & 0 & 0.0 & 0.0 & 1 & 4.7 & 2.9 \\
\hline$P f+P v+P m$ & I & 4.3 & 2.5 & 99 & 63.0 & 20.6 \\
\hline$P f+P v+P o$ & 0 & 0.0 & 0.0 & 33 & 20.5 & 7.6 \\
\hline $\mathrm{Pf}+\mathrm{Pm}+\mathrm{Po}$ & 0 & 0.0 & 0.0 & 8 & 5.7 & 0.9 \\
\hline $\mathrm{Pv}+\mathrm{Pm}_{\mathrm{m}}+\mathrm{Po}_{0}$ & 0 & 0.0 & 0.0 & 6 & 2.6 & 4.4 \\
\hline \multirow[t]{3}{*}{$\mathrm{Pf}+\mathrm{Pv}+\mathrm{Pm}+\mathrm{Po}$} & 0 & 0.0 & 0.0 & 17 & 3.2 & 60.4 \\
\hline & & Total: & 37.9 & & Total: & 167.0 \\
\hline & & & $P<0.001$ & & & $P<0.001$ \\
\hline
\end{tabular}

I Expected values calculated under multiple kind lottery model ${ }^{2} \mathrm{X}^{2}$ calculated as (Observed-Expected) ${ }^{2} /$ Expected

$\mathrm{Pf}=P$. falciparum, $\mathrm{Pv}=P$. vivax, $\mathrm{Pm}=P$. malariae, $\mathrm{Po}=P$. ovale

$26.4 \%$ ), $6.4 \%$ to $25.1 \%$ for $P$. vivax (CV: $39.8 \%$ ), $0.6 \%$ to $15.4 \%$ for P. malariae (CV: $94.5 \%$ ) and $32.0 \%$ to $67.6 \%$ for any Plasmodium infections (CV: 21.9\%). P. vivax and $P$. malariae infections were found more commonly in the villages in the foot hills (Ulupu (P. vivax only), Brukham \& Ilaita) compared to the villages situated on the Sepik River flood plain. The prevalence of LDR-FMA detectable infections were significantly associated with those by LM $(P$. falciparum: $\mathrm{r}^{2}=0.65, \mathrm{p}=0.008, P$. vivax: $\mathrm{r}^{2}=0.67, \mathrm{p}=$ 0.007, P. malariae: $\left.\mathrm{r}^{2}=0.85, \mathrm{p}<0.001\right)$. Although variation in infection prevalence between villages was less pronounced ( $P$. falciparum: $35.0 \%$ to $78.7 \%, \mathrm{CV}: 17.8 \%$ ); $P$. vivax: $22.9 \%$ to $45.2 \%, \mathrm{CV}: 16.8 \%$; P. malariae: $2.5 \%$ to $30.9 \%$, CV: $55.3 \%$ ); P. ovale: $1.2 \%$ to $9.0 \%$, CV: $45.3 \%$ and any infection: $59.1 \%$ to $85.6 \%, \mathrm{CV}: 17.8 \%$ ), broadly similar geographical trends were observed. Interestingly, prevalence of any malaria infection by both LM and LDRFMA was significantly associated with a lower population mean Hb level (LM: $\mathrm{r}^{2}=-0.69, \mathrm{p}=0.004$; LDR-FMA: $\mathrm{r}^{2}=-$ $0.75, \mathrm{p}=0.001$ ) and a higher incidence of moderate-tosevere anaemia $\left(\mathrm{Hb}<8 \mathrm{~g} / \mathrm{dl}, \mathrm{LM}: \mathrm{r}^{2}=0.61, \mathrm{p}=0.016\right.$ LDR-FMA: $\left.\mathrm{r}^{2}=0.65, \mathrm{p}=0.009\right)$. When diagnosed by LM, the reductions in age- and gender-adjusted $\mathrm{Hb}$ levels were most strongly associated with the presence of a mixed infection $\left(-1.2 \mathrm{~g} / \mathrm{dl}, \mathrm{CL}_{95}\right.$ : 0.9-1.4, $\left.\mathrm{p}<0.001\right)$, followed by P. malariae $\left(-0.6 \mathrm{~g} / \mathrm{dl}, \mathrm{CL}_{95}: 0.3-0.9, \mathrm{p}<0.001\right), P$. falci- parum $\left(-0.5 \mathrm{~g} / \mathrm{dl}, \mathrm{CL}_{95}: 0.4-0.7, \mathrm{p}<0.001\right)$ and $P$. vivax single infections $\left(-0.3 \mathrm{~g} / \mathrm{dl}_{1} \mathrm{CL}_{95}: 0.1-0.5, \mathrm{p}=0.005\right)$. Among LDR-FMA diagnosed infections only mixed species $\left(-0.4 \mathrm{~g} / \mathrm{dl}, \mathrm{CL}_{95}: 0.2-0.5, \mathrm{p}<0.001\right)$ and $P$. falciparum single infections $\left(-0.5 \mathrm{~g} / \mathrm{dl}, \mathrm{CL}_{95}: 0.3-0.7, \mathrm{p}<0.001\right)$ were associated with a significant reduction in $\mathrm{Hb}$ levels. $\mathrm{Hb}$ reductions were larger in children than adults and adolescents.

The Bayesian estimation of among-area and villagewithin-area variance components revealed differences in scale of this geographical variation in risk of infection among the different Plasmodium species and between methods of diagnosis (Table 5). Among LM diagnosed infection, area-specific differences accounted for only $11.5 \%$ of variation in rates of infection with P. falciparum, but for $54.9 \%$ and $53.7 \%$ of variation in rates of $P$. vivax and $P$. malariae infections respectively. With LDR-FMA the proportion of location-structured variation increased to $53.8 \%$ for $P$. falciparum, $88.1 \%$ for $P$. vivax and $83.7 \%$ for $P$. malariae, $86.4 \%$ of variation in rates of $P$. ovale infections was observed between sites.

The prevalence of Plasmodium species infections was significantly reduced in villages with higher ITN coverage (Figure 3). Such a negative association was observed for 
Table 3: Associations between infections with different Plasmodium species as observed by different diagnostic techniques.

\begin{tabular}{|c|c|c|c|c|c|c|}
\hline & \multicolumn{3}{|c|}{ Light microscopy } & \multicolumn{3}{|c|}{ LDR - FMA } \\
\hline & $\mathbf{O R}^{\prime}$ & $\mathrm{CL}_{95}$ & P-value & $\mathbf{O R}^{\prime}$ & $\mathrm{CL}_{95}$ & P-value \\
\hline \multicolumn{7}{|l|}{ Overall } \\
\hline Pf vs Pv & 0.69 & {$[0.53,0.90]$} & 0.004 & 1.12 & {$[0.96,1.34]$} & 0.145 \\
\hline Pf vs Pm & 0.25 & {$[0.11,0.49]$} & $<0.001$ & 3.14 & {$[2.39,4.15]$} & $<0.001$ \\
\hline Pf vs Po & -- & & & 2.00 & {$[1.33,3.07]$} & $<0.001$ \\
\hline Pv vs Pm & 0.37 & {$[0.13,0.84]$} & 0.014 & 1.49 & {$[1.17,1.89]$} & $<0.001$ \\
\hline $\mathrm{Pv}$ vs Po & -- & & & 2.00 & {$[1.39,2.98]$} & $<0.001$ \\
\hline Pm vs Po & -- & & & 2.47 & {$[1.56,3.81]$} & $<0.001$ \\
\hline \multicolumn{7}{|c|}{ Children $<10$ yrs } \\
\hline Pf vs Pv & 0.71 & {$[0.52,0.97]$} & 0.034 & 1.04 & {$[0.81,1.34]$} & 0.761 \\
\hline Pf vs Pm & 0.41 & {$[0.17,1.00]$} & 0.049 & 6.78 & {$[3.63,12.67]$} & $<0.001$ \\
\hline Pf vs Po & -- & & & 2.50 & {$[1.29,4.82]$} & 0.006 \\
\hline $\mathrm{Pv}$ vs $\mathrm{Pm}$ & 0.41 & {$[0.14,1.17]$} & 0.096 & 1.09 & {$[0.70,1.70]$} & 0.713 \\
\hline Pv vs Po & -- & & & 1.97 & {$[1.07,3.63]$} & 0.029 \\
\hline $\mathrm{Pm}$ vs $\mathrm{Po}$ & -- & & & 6.19 & {$[3.18,12.05]$} & $<0.001$ \\
\hline \multicolumn{7}{|c|}{ Adolescents $\&$ adults $>=10 \mathrm{yrs}$} \\
\hline Pf vs Pv & 0.38 & {$[0.22,0.65]$} & $<0.001$ & 1.30 & {$[1.04,1.63]$} & 0.020 \\
\hline Pf vs Pm & 0.17 & {$[0.06,0.46]$} & 0.001 & 2.37 & {$[1.76,3.21]$} & $<0.001$ \\
\hline Pf vs Po & -- & & & 1.74 & {$[1.06,2.87]$} & 0.030 \\
\hline Pv vs Pm & 0.35 & {$[0.08,1.44]$} & 0.145 & 1.96 & {$[1.49,2.59]$} & $<0.001$ \\
\hline Pr vs Po & -- & & & 2.15 & {$[1.35,3.42]$} & 0.001 \\
\hline $\mathrm{Pm}$ vs $\mathrm{Po}$ & -- & & & 1.51 & {$[0.66,2.62]$} & 0.150 \\
\hline
\end{tabular}

I OR: Odd-ratio. $O R<I$ indicated negative, $O R>I$ a positive association, $C L_{95}$ : $95 \%$ confidence limit

$P f=P$. falciparum, $\mathrm{Pv}=P$. vivax, $\mathrm{Pm}=P$. malariae, $\mathrm{Po}=P$. ovale

all species when diagnosed by LDR-FMA ( $\mathrm{r}^{2}:-0.59$ to $0.82, \mathrm{p}<0.05)$ as well as $P$. vivax $\left(\mathrm{r}^{2}:-0.69, \mathrm{p}<0.01\right)$ and $P$. malariae $\left(\mathrm{r}^{2}:-0.77, \mathrm{p}<0.001\right)$ but not $P$. falciparum $\left(\mathrm{r}^{2}\right.$ : $-0.15)$ when diagnosed by LM. Accounting for differences in bednet coverage among villages consequently reduced total spatial variance by $56-85 \%$ for all species and both diagnostic methods, except for LM-diagnosed P. falciparum infections $(-2 \%)$. In contrast, substantial differences were observed between the two diagnostic methods and between Plasmodium species in regard to the spatial level at which the effect of bednet coverage was most pronounced (Table 5). Among LDR-FMA diagnosed infections, bednet coverage was associated with a comparable reduction in among-area and village-within-area variances of $P$. malariae and $P$. ovale prevalence rates, but a stronger reduction in among-area variance was observed for $P$. falciparum and $P$. vivax. Among LM diagnosed $P$. malariae infections, reduction in among-area variance were comparable to those observed at village-level, while the increased reduction in among-area variance of $P$. vivax infection was even more pronounced than among LDRFMA diagnosed infection. Adjusting for bednet coverage further increased the differences in the proportion of spatial variance observed at among-area level variance observed in LM (13-41\%) compared to LDR-FMA diagnosed infection (34-90\%).

\section{Discussion}

With over 2,500 samples processed, the present study is the largest epidemiological study to-date that has used a post-PCR LDR-FMA assay for the diagnosis of malarial infection on all samples collected. The direct comparison of LM and LDR-FMA results confirmed that the LDR-FMA assay is both significantly more sensitive than LM and semi-quantitative $[23,24]$, with the increased sensitivity most notable for $P$. malariae and $P$. ovale infections.

The higher sensitivity of the LDR-FMA in detecting low density infection was most notable in the assessment of mixed species assemblages and in age-specific prevalence. In concordance with the observations by Kasehagen et al. [24], a significant deficit of mixed species infections was observed in LM diagnosis, but an excess of high-level mixed infections, and interestingly also of uninfected study participants, were detected by LDR-FMA diagnosis. Prevalence of infections detected by LDR-FMA peaked at a later age than did infections diagnosed by LM (Figure 2), confirming that adolescents and adults contribute significantly more to the total burden of infections in a population than appreciated when only LM diagnosis is used [24]. Having observed the same patterns of infections in two independent surveys suggests that similar changes 
Table 4: Multivariate predictors of malarial infections in study populations.

\begin{tabular}{|c|c|c|c|c|c|c|c|c|c|c|}
\hline & & \multicolumn{4}{|c|}{ Light microscopy } & \multicolumn{5}{|c|}{ LDR - FMA } \\
\hline & & Pf & $\mathbf{P v}$ & Pm & All & Pf & $\mathbf{P v}$ & Pm & Po & All \\
\hline \multirow[t]{2}{*}{ Bednet coveragel } & AOR & $0.90 * * *$ & & $0.62 * * *$ & $0.78^{* * * *}$ & $0.79 * * *$ & & $0.69 * * *$ & $0.80^{* * *}$ & $0.80 * * *$ \\
\hline & $\mathrm{CL}_{95}$ & {$[0.85,0.95]$} & & {$[0.55,0.70]$} & {$[0.74,0.82]$} & {$[0.74,0.83]$} & & {$[0.64,0.74]$} & {$[0.72,0.90]$} & {$[0.74,0.85]$} \\
\hline \multirow{2}{*}{$\begin{array}{c}\text { Bednet coverage > } \\
90 \%\end{array}$} & $A O R$ & & $0.43^{* * *}$ & & & & $0.63^{* * *}$ & & & \\
\hline & $\mathrm{CL}_{95}$ & & {$[0.34,0.56]$} & & & & {$[0.53,0.74]$} & & & \\
\hline \multirow{2}{*}{$\begin{array}{l}\text { Mother speaks } \\
\text { English }\end{array}$} & $A O R$ & $0.56 * * *$ & & & $0.77^{*}$ & $0.61 * * *$ & & $0.50 * *$ & & \\
\hline & $\mathrm{CL}_{95}$ & {$[0.41,0.76]$} & & & {$[0.59,0.99]$} & {$[0.47,0.7]$} & & {$[0.41,0.93]$} & & \\
\hline \multirow{2}{*}{$\begin{array}{c}\text { Mother }>6 \text { yrs } \\
\text { education }\end{array}$} & $A O R$ & & & & & & $0.72^{*}$ & & & $0.64 * *$ \\
\hline & $\mathrm{CL}_{95}$ & & & & & & {$[0.53,0.99]$} & & & {$[0.46,0.88]$} \\
\hline \multicolumn{11}{|l|}{ Economic Status } \\
\hline \multirow[t]{2}{*}{ Medium } & AOR & $0.74^{*}$ & & & & & & & & \\
\hline & $\mathrm{CL}_{95}$ & {$[0.58,0.93]$} & & & & & & & & \\
\hline \multirow[t]{2}{*}{ High } & AOR & $0.59 * * *$ & & & $0.82 *$ & $0.75 * *$ & & & & $0.77 * *$ \\
\hline & $\mathrm{CL}_{95}$ & {$[0.46,0.75]$} & & & {$[0.69,0.98]$} & {$[0.47,0.79]$} & & & & {$[0.64,0.93]$} \\
\hline \multirow[t]{2}{*}{ No windows } & AOR & & & & & $1.36 *$ & & & & \\
\hline & $\mathrm{CL}_{95}$ & & & & & {$[1.04,1.78]$} & & & & \\
\hline \multirow[t]{2}{*}{ Screened windows } & $A O R$ & & & & & & & $0.33 * * *$ & & \\
\hline & $\mathrm{CL}_{95}$ & & & & & & & {$[0.17,0.67]$} & & \\
\hline \multirow[t]{2}{*}{ Walls from Sago palm } & AOR & & & & & & & $0.46^{*}$ & & \\
\hline & $\mathrm{CL}_{95}$ & & & & & & & {$[0.24,0.89]$} & & \\
\hline \multirow[t]{2}{*}{ Modern toilet ${ }^{2}$} & AOR & & & & & & & & & $0.66^{*}$ \\
\hline & $\mathrm{CL}_{95}$ & & & & & & & & & {$[0.45,0.97]$} \\
\hline
\end{tabular}

I Effect associated with a $10 \%$ increase in net use among all participants in study village

2 Flush toilet or pit latrine with cement floor

AOR: Age-adjusted odd-ratio, $C L_{95}$ : $95 \%$ confidence limit. $* * * p<0.001$, $* * p<0.01$, * $p<0.05$.

Table 5: Posterior medians of among-area and village-within-area variance components.

\begin{tabular}{|c|c|c|c|c|c|c|c|c|c|}
\hline & Pf & $\mathbf{P v}$ & Pm & All & Pf & $\mathbf{P v}$ & Pm & Po & All \\
\hline \multicolumn{10}{|l|}{ Age adjusted } \\
\hline Areas & 0.023 & 0.259 & 0.554 & 0.125 & 0.180 & 0.108 & 0.726 & 0.221 & 0.233 \\
\hline Villages within area & 0.174 & 0.231 & 0.503 & 0.213 & 0.165 & 0.018 & 0.149 & 0.046 & 0.050 \\
\hline$\%$ between-area' & $11.5 \%$ & $54.9 \%$ & $53.7 \%$ & $37.6 \%$ & $53.8 \%$ & $88.1 \%$ & $83.6 \%$ & $86.4 \%$ & $84.4 \%$ \\
\hline \multicolumn{10}{|l|}{ Age + bednet adjusted } \\
\hline Areas & 0.031 & 0.026 & 0.060 & 0.023 & 0.048 & 0.042 & 0.225 & 0.060 & 0.059 \\
\hline Villages within area & 0.163 & 0.175 & 0.102 & 0.133 & 0.091 & 0.013 & 0.033 & 0.017 & 0.015 \\
\hline \% between-area' & $15.9 \%$ & $12.6 \%$ & $41.2 \%$ & $14.7 \%$ & $34.0 \%$ & $80.2 \%$ & $89.9 \%$ & $80.1 \%$ & $82.6 \%$ \\
\hline \multicolumn{10}{|l|}{ Relative change $^{2}$} \\
\hline Areas & $+36.6 \%$ & $-90.0 \%$ & $-89.2 \%$ & $-81.8 \%$ & $-73.4 \%$ & $-60.6 \%$ & $-69.0 \%$ & $-73.0 \%$ & $-74.5 \%$ \\
\hline Villages within area & $-6.7 \%$ & $-24.4 \%$ & $-79.6 \%$ & $-37.8 \%$ & $-44.6 \%$ & $-29.5 \%$ & $-78.2 \%$ & $-61.7 \%$ & $-69.4 \%$ \\
\hline Total spatial variance ${ }^{3}$ & $-1.6 \%$ & $-59.1 \%$ & $-84.6 \%$ & $-54.1 \%$ & $-59.7 \%$ & $-56.2 \%$ & $-70.6 \%$ & $-71.1 \%$ & $-73.6 \%$ \\
\hline
\end{tabular}

\footnotetext{
I Proportion of among-area variance of total spatial variance measured on a logit scale (i.e. $\sigma_{\mathrm{i}(\mathrm{i})} /\left(\sigma_{\mathrm{i}(\mathrm{i})+} \theta_{\mathrm{i}(\mathrm{i}) \mathrm{k}(\mathrm{i})}\right.$, see methods). Posterior median estimated from model does not exactly correspond proportion calculated from posterior medians of individual variances.

2 Relative chance of posterior median of variance components from bed-net adjusted to non-adjusted model.

${ }^{3}$ Sum of posterior medians of among-area and village-within-area variance components (i.e. $\left.\sigma_{\mathrm{j}(\mathrm{i})+} \theta_{\mathrm{j}(\mathrm{i}) \mathrm{k}(\mathrm{i})}\right)$

$\mathrm{Pf}=\mathrm{P}$. falciparum, $\mathrm{Pv}=\mathrm{P}$. vivax, $\mathrm{Pm}=P$. malariae, $\mathrm{Po}=P$. ovale
} 

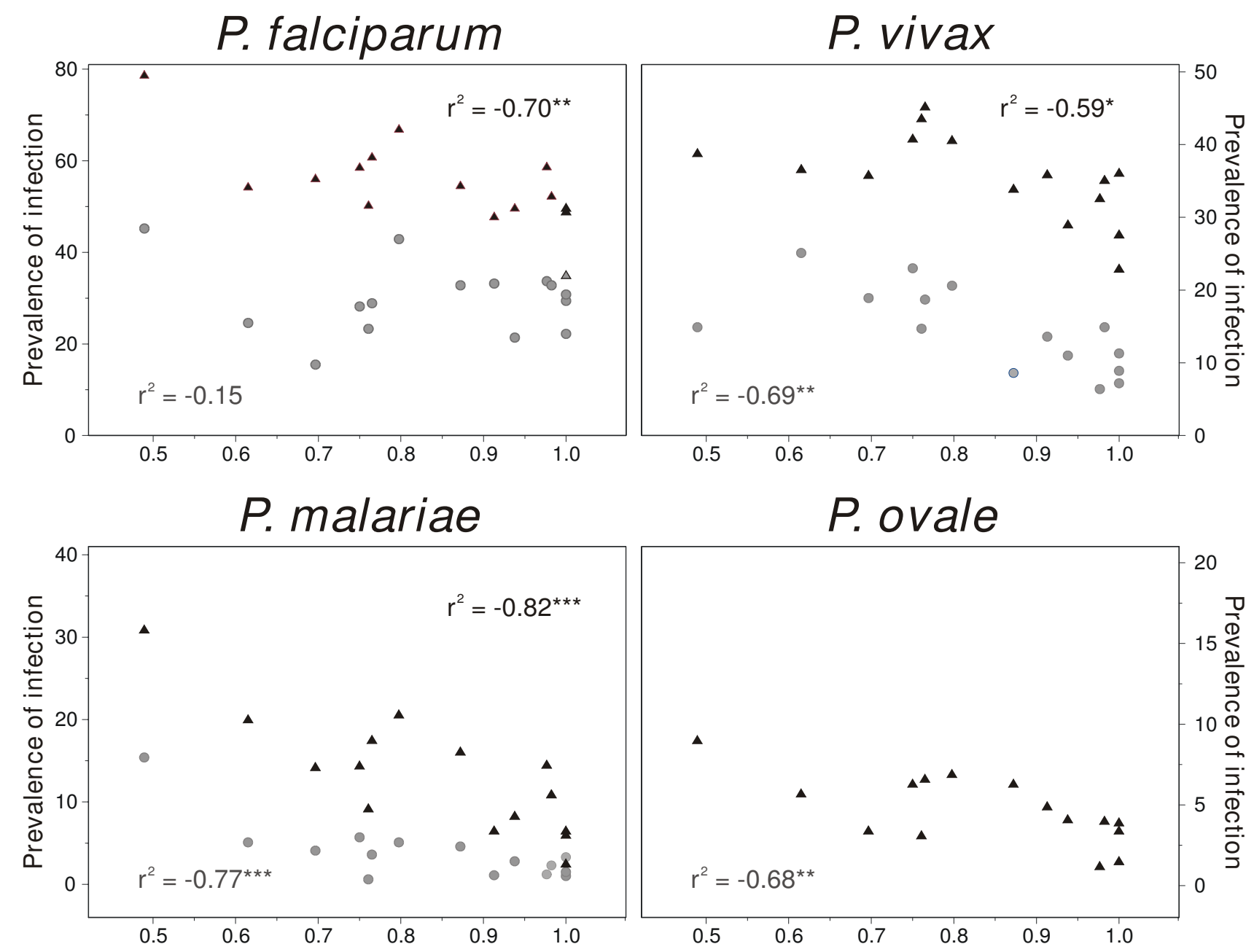

Any infection

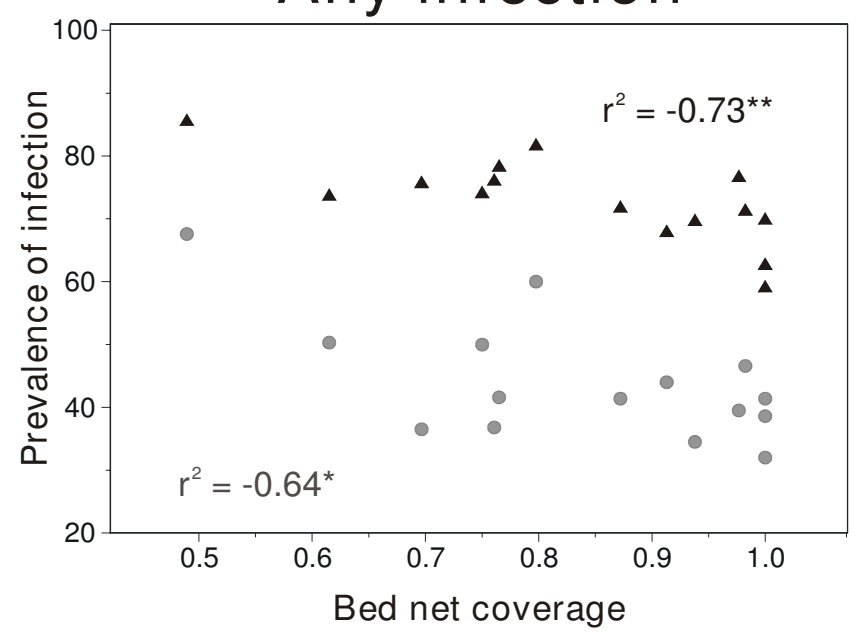

P. ovale

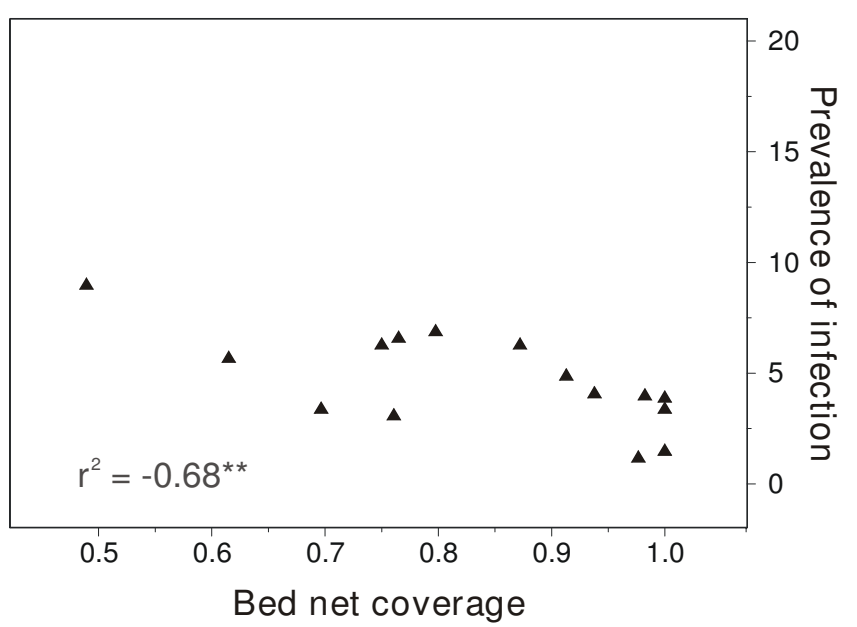

\section{- LDR-FMA diagnosed}

LM diagnosed

Figure 3

Association of bednet coverage and parasite prevalence rates in I 5 study villages. $* * * p<0.00 I, * * p<0.0 I, * p<$ 0.05 . 
may be generally observed when PCR-based diagnosis is used in epidemiological studies.

Associations between different Plasmodium species have long been a subject of investigation, but results have been inconsistent and inconclusive (see the review by Richie [13]). Since the vectors of different Plasmodia are the same, it may be expected that the different parasites would be associated, unless there is immune-mediated competition, species-specific difference in red blood cell susceptibility. Meta-analysis of 19 studies by McKenzie and Bossert [15] found a tendency for statistically significant surplus of mixed infections by $P$. falciparum-P. malariae-P. ovale and for deficits in $P$. falciparum-P. malariae-P. vivax. The present analyses suggest that these deficits may be artifacts of the lower sensitivity of LM, since they were seen in the PNG data only when the assessment was made by LM. This is further highlighted by the weaker negative association in children under 10 that have a lower immune status and thus a more limited control of parasitaemia [30]. A recent series of cross-sectional studies in Malawi [31] that used PCR for diagnosis also found an significant increase of mixed infection that we more pronounced in adults than children. These observations are consistent with a suggestion [13] that parasite densities may be suppressed by co-infections, but that co-infections do not prevent blood stage infections, or stimulate crossspecies immunity capable of limiting infections.

With both diagnostic methods considerable variation in prevalence of infections was observed among villages for all Plasmodium species. While prevalence by LM and LDRFMA was strongly correlated and overall geographical patterns comparable, LM-based prevalence showed a much higher degree of variability within individual areas for all Plasmodium species than LDR-FMA-based prevalence. In particular, for the non-falciparum species, almost all spatial variation in LDR-FMA-based rates of infection was observed as difference between areas. The proportionally higher within area variance is likely to be related to the lower sensitivity of LM (both for low-level infection and correct identification of infecting species). Differences in the quality of different slide batches, or between-reader variation may further contribute to within-area variation. In intervention trials where more than one slide is made and all slides have at least two independent reads these types of variability may be reduced. In large scale epidemiology studies or in monitoring of malaria interventions where thousands of people are screened, this is not necessarily common practice. If the trend for a decrease in survey-to-survey variation in PCR-based diagnosis holds true elsewhere, the heterogeneity of malaria risk at the local level may have been overestimated in earlier studies. Results of this nature would emphasize the importance of implementing molecular diagnostic methods.
Interestingly, the least amount of between area variation (by both LM and LDR-FMA) was observed in the most common parasites, i.e. P. falciparum. Whether this reflects a true difference in ecology of different Plasmodium species in the study area is difficult to determine from a single cross-sectional survey. In addition, multiple P. falciparum strain infections are commonly observed in PNG [32] and the true amount of geographical difference in transmission may be obscured if only presence or absence, but not the number of infecting strains were detected.

The coverage of ITNs in a given village was the best predictor of risk of malaria infections at individual and village levels. Both high coverage of ITNs in the village of residence as well as personal ITN use significantly reduced a participant's risk of being infected with any of the human malaria species. Interestingly, personal use was less strongly associated with protection (data not shown) than overall coverage in a given village. This suggests that if high coverage is achieved, ITN may have an effect on overall transmission and thereby also protect people who do not always sleep under a ITN [33]. The protective effect of ITNs against $P$. falciparium is well described [34] and there increasing evidence for their effectiveness against $P$. vivax, although the effect may be smaller than that against $P$. falciparum [35-37]. To date there has been very little information on the effect of ITNs on P. malariae and P. ovale. While ITNs were highly effect in reducing $P$. malariae in a study in Burkina Faso[38], this may be the first description of an effect of ITNs on risk of $P$. ovale infections.

Differences in ITN coverage among villages also reduced total spatial variance of Plasmodium infections (measured on the logistic scale) by up to $85 \%$. Similar spatial associations of coverage in untreated bednets with reduced (peak) prevalence and increased age at peak prevalence were observed $P$. falciparum, $P$. vivax and $P$. malariae in earlier studies in the Wosera [27]. In addition, high coverage of untreated bednets led to significant reduction in sporozoite rates in mosquito vectors [39]. In African studies high ITN coverage reduced $P$. falciparum transmission by up to $90 \%[11,40]$. Therefore, it is very likely that if sufficiently high coverage rates can be achieved, the ongoing PNG national bednet distribution program will not only reduce the burden of illness, but also have an impact of prevalence of infections. The very high reductions in between-area variation in $P$. malariae and $P$. ovale prevalence suggest that ITNs may be quite effective for the control of these species, while control of $P$. vivax may be more difficult as indicated by the smallest reduction in spatial variation (by LDR-FMA). Interestingly, the variation in prevalence of infection was closely linked to a difference in mean haemoglobin levels in the study villages, indicating that control of malaria through ITNs may also result in improved haemoglobin levels. Given the well known 
problems with spurious correlations in ecological comparisons, these associations with ITN coverage need to be interpreted with care. Direct evaluation of the ongoing PNG national bednet distribution program on the transmission of non-falciparum species is needed.

The only other factor consistently associated with a reduced prevalence of Plasmodium infections is the level of maternal education. It is well know that educated mothers have a better understanding of health, seek treatment more promptly, and use ITN more regularly [41-43] than uneducated mothers $[44,45]$. Similarly, higher socioeconomic status is generally associated with better health outcomes. Interestingly, there was no consistent association of house-type with prevalence of malaria infections of any species. This suggests that different housing types are similarly attractive to the local mosquito vector species. The tendency of many PNG anophelines to bite outdoors readily in the early or late hours of the night [46] may further reduce any effect of different house types on risk of Plasmodium species infection.

The present study demonstrates that application of the high-throughput, PCR-based LDR-FMA diagnostic assay is feasible in large malaria field studies. Additionally, results show that epidemiological patterns of malaria risk detected by molecular diagnosis differ significantly from risk assessed by LM. Overall, results from this study enhance our understanding of the impact that low level asymptomatic infection, infection in older age groups, and infection by less common malaria parasites contributes to the burden and transmission of Plasmodium species infections. In combination with high-throughput Plasmodium strain typing assays $[47,48]$ and novel approaches to define the levels of gametocytemia[49], the accurate classification of Plasmodium infections in the field and the understanding of malaria epidemiology is significantly improved., Future large scale malaria field studies and, in particular, intervention trials would therefore benefit significantly by improving capacity for molecular diagnosis of Plasmodium infections. Increased investment into establishing molecular diagnosis capacity in malaria endemic countries should be considered a high priority.

\section{Competing interests}

The authors declare that they have no competing interests.

\section{Authors' contributions}

IM designed the study, analysed the data and wrote the first draft. SW, DM, SM, BK AS conducted the field work and read blood slides. SW and DM also assisted in data analyses. DTM and PAZ conducted LDR-FMA typing of all samples. TAS assisted with the spatial data analyses. All authors contributed to the interpretation of the data and the writing of manuscript.

\section{Additional material}

\section{Additional file 1}

Table S1. Comparison of observed species mixtures in different regions by LDR-FMA.

Click here for file

[http://www.biomedcentral.com/content/supplementary/1475-

2875-8-41-S1.pdf]

\section{Additional file 2}

Table S2. Comparison of observed species mixtures in different regions by light microscopy.

Click here for file

[http://www.biomedcentral.com/content/supplementary/1475-

2875-8-41-S2.pdf]

\section{Acknowledgements}

First and foremost, we could like to thank all members of study communities that participated in the surveys. We thank Lawrence Rare and Jim Wildig for assistance with the field work and Rex Ivivi and Jonah Iga for assistance with microscopy. Finally, we thank Dr. Charles King for critical comments leading to completion of this manuscript. This work as supported with funding from National Institutes of Health (AI063135, Al46919, and TW007872) and AusAID.

\section{References}

I. Haworth J: The global distribution of malaria and the present control effort. In Malaria - Principle and Practice of Malariology Volume 2. Edited by: Wernsdorfer WH, McGregor IA. Edinburgh: Churchill Livingstone; I988: |379-|420.

2. Snow RW, Guerra CA, Noor AM, Myint HY, Hay SI: The global distribution of clinical episodes of Plasmodium falciparum malaria. Nature 2005, 434:214-217.

3. Briet OJ, Gunawardena DM, Hoek W van der, Amerasinghe FP: Sri Lanka malaria maps. Malar J 2003, 2:22.

4. Gemperli A, Sogoba N, Fondjo E, Mabaso M, Bagayoko M, Briet OJ, Anderegg D, Liebe J, Smith T, Vounatsou P: Mapping malaria transmission in West and Central Africa. Trop Med Int Health 2006, I I: 1032-1046.

5. Kazembe LN, Kleinschmidt I, Holtz TH, Sharp BL: Spatial analysis and mapping of malaria risk in Malawi using point-referenced prevalence of infection data. Int J Health Geogr 2006, 5:4I.

6. Omumbo JA, Hay SI, Snow RW, Tatem AJ, Rogers DJ: Modelling malaria risk in East Africa at high-spatial resolution. Trop Med Int Health 2005, 10:557-566.

7. Cattani JA, Moir JS, Gibson FD, Ginny M, Paino J, Davidson W, Alpers MP: Small-area variations in the epidemiology of malaria in Madang Province. PN G Med J 1986, 29(I): I I-I7.

8. Incardona S, Vong S, Chiv L, Lim P, Nhem S, Sem R, Khim N, Doung $S$, Mercereau-Puijalon $O$, Fandeur T: Large-scale malaria survey in Cambodia: novel insights on species distribution and risk factors. Malar J 2007, 6:37.

9. Kleinschmidt I, Sharp B, Mueller I, Vounatsou P: Rise in malaria incidence rates in South Africa: a small-area spatial analysis of variation in time trends. Am J Epidemiol 2002, I 55:257-264.

10. Sogoba N, Vounatsou P, Doumbia S, Bagayoko M, Toure MB, Sissoko IM, Traore SF, Toure YT, Smith T: Spatial analysis of malaria transmission parameters in the rice cultivation area of Office du Niger, Mali. Am J Trop Med Hyg 2007, 76:1009-10I5.

II. Maxwell CA, Chambo W, Mwaimu M, Magogo F, Carneiro IA, Curtis CF: Variation of malaria transmission and morbidity with altitude in Tanzania and with introduction of alphacypermethrin treated nets. Malar J 2003, 2:28.

12. Mbogo CM, Mwangangi JM, Nzovu J, Gu W, Yan G, Gunter JT, Swalm C, Keating J, Regens JL, Shililu JI, et al.: Spatial and temporal heterogeneity of Anopheles mosquitoes and Plasmodium falci- 
parum transmission along the Kenyan coast. Am J Trop Med Hyg 2003, 68:734-742

13. Richie TL: Interactions between malaria parasites infecting the same vertebrate host. Parasitology 1988, 96:607-639.

14. McKenzie FE, Bossert WH: Mixed-species Plasmodium infections of humans. J Parasitol 1997, 83:593-600.

15. McKenzie FE, Bossert WH: Multispecies Plasmodium infections of humans. J Parasitol 1999, 85: 12-18.

16. Zimmerman PA, Mehlotra RK, Kasehagen LJ, Kazura JW: Why do we need to know more about mixed Plasmodium species infections in humans? Trends Parasitol 2004, 20:440-447.

17. Snounou G, Pinheiro L, Goncalves A, Fonseca L, Dias F, Brown KN, do $R, V E$ : Identification of the four human malaria parasite species in field samples by polymerase chain reaction and detection of a high prevalence of mixed infections. Mol Biochem Parasitol 1993, 58:283-292.

18. Mehlotra RK, Kasehagen LJ, Baisor M, Lorry K, Kazura JW, Bockarie MJ, Zimmerman PA: Malaria infections are randomly distributed in diverse holoendemic areas of Papua New Guinea. Am J Trop Med Hyg 2002, 67:555-562.

19. Mehlotra RK, Lorry K, Kastens W, Miller SM, Alpers MP, Bockarie M, Kazura JW, Zimmerman PA: Random distribution of mixed species malaria infections in Papua New Guinea. Am J Trop Med Hyg 2000, 62:225-231.

20. Coleman RE, Sattabongkot J, Promstaporm S, Maneechai N, Tippayachai B, Kengluecha A, Rachapaew N, Zollner G, Miller RS, Vaughan JA, et al.: Comparison of PCR and microscopy for the detection of asymptomatic malaria in a Plasmodium falciparuml vivax endemic area in Thailand. Malar J 2006, 5:121.

21. Muller I, Bockarie M, Alpers M, Smith T: The epidemiology of malaria in Papua New Guinea. Trends Parasitol 2003, 19:253-259.

22. Mueller I, Zimmerman PA, Reeder JC: Plasmodium malariae and Plasmodium ovale - the "bashful" malaria parasites. Trends Parasitol 2007, 23:278-283.

23. McNamara DT, Kasehagen LJ, Grimberg BT, Cole-Tobian J, Collins WE, Zimmerman PA: Diagnosing infection levels of four human malaria parasite species by a polymerase chain reaction/ ligase detection reaction fluorescent microsphere-based assay. Am J Trop Med Hyg 2006, 74:4I 3-42I.

24. Kasehagen LJ, Mueller I, McNamara DT, Bockarie MJ, Kiniboro B, Rare L, Lorry K, Kastens W, Reeder JC, Kazura JW, Zimmerman PA: Changing patterns of Plasmodium blood-stage infections in the Wosera region of Papua New Guinea monitored by light microscopy and high throughput PCR diagnosis. Am J Trop Med Hyg 2006, 75:588-596.

25. Michon P, Cole-Tobian JL, Dabod E, Schoepflin S, Igu J, Susapu M, Tarongka N, Reeder JC, Beeson JG, Schofield L, King CL, Mueller I: The risk of malarial infections and disease in Papua New Guinean children. Am J Trop Med Hyg 2007, 76:997-1008.

26. Genton B, Al Yaman F, Beck HP, Hii J, Mellor S, Narara A, Gibson N, Smith T, Alpers MP: The epidemiology of malaria in the Wosera area, East Sepik Province, Papua New Guinea, in preparation for vaccine trials. I. Malariometric indices and immunity. Ann Trop Med Parasitol 1995, 89:359-376.

27. Smith T, Hii JL, Genton B, Muller I, Booth M, Gibson N, Narara A Alpers MP: Associations of peak shifts in age - prevalence for human malarias with bednet coverage. Trans $R$ Soc Trop Med Hyg 200I, 95:I-6.

28. McNamara DT, Thomson JM, Kasehagen LJ, Zimmerman PA: Development of a multiplex PCR-ligase detection reaction assay for diagnosis of infection by four human malaria parasite species. J Clin Microbol 2004, 42:2403-24I0.

29. Lunn DJ, Thomas A, Best N, Spiegelhalter D: WinBUGS - a Bayesian modelling framework: concepts, structure, and extensibility. Statistics and Computing 2000, 10:325-337.

30. Michon P, Cole-Tobian JL, Dabod E, Schoepflin S, Igu J, Susapu M, Tarongka N, Zimmerman PA, Reeder JC, Beeson JG, Schofield L, Kin $\mathrm{CL}$, Mueller I: The risk of malarial infections and disease in Papua New Guinean children. Am J Trop Med Hyg 2007, 76:997-1008

31. Bruce MC, Macheso A, Kelly-Hope LA, Nkhoma S, McConnachie A, Molyneux ME: Effect of Transmission Setting and Mixed Species Infections on Clinical Measures of Malaria in Malawi. PLoS One 2008, 3:e2775.

32. Bruce MC, Galinski MR, Barnwell JW, Donnelly CA, Walmsley M, Alpers MP, Walliker D, Day KP: Genetic diversity and dynamics of Plasmodium falciparum and $P$. vivax populations in multiply infected children with asymptomatic malaria infections in Papua New Guinea. Parasitology 2000, I 2 I:257-272.

33. Hawley WA Phillips-Howard PA, ter Kuile FO, Terlouw DJ, Vulule JM, Ombok M, Nahlen BL, Gimnig JE, Kariuki SK, Kolczak MS, Hightower AW: Community-wide effects of permethrin-treated bed nets on child mortality and malaria morbidity in western Kenya. Am J Trop Med Hyg 2003, 68(4 Suppl): I2I-I27.

34. Lengeler $\mathrm{C}$ : Insecticide-treated bed nets and curtains for preventing malaria. Cochrane Database Syst Rev 2004, 2:CD000363.

35. Luo D, Lu D, Yao R, Li P, Huo X, Li A, Wen L, Ge C, Zhang S, Huo $\mathrm{H}$ : Alphamethrin-impregnated bed nets for malaria and mosquito control in China. Trans $R$ Soc Trop Med Hyg 1994, 88:625-628

36. Richards FO Jr, Klein RE, Flores RZ, Weller S, Gatica M, Zeissig R, Sexton J: Permethrin-impregnated bed nets for malaria control in northern Guatemala: epidemiologic impact and community acceptance. Am J Trop Med Hyg 1993, 49:4I0-4I8.

37. Rowland M, Bouma M, Ducornez D, Durrani N, Rozendaal J, Schapira A, Sondorp E: Pyrethroid-impregnated bed nets for personal protection against malaria for Afghan refugees. Trans $R$ Soc Trop Med Hyg 1996, 90:357-36।

38. Habluetzel A, Cuzin N, Diallo DA, Nebie I, Belem S, Cousens SN, Esposito F: Insecticide-treated curtains reduce the prevalence and intensity of malaria infection in Burkina Faso. Trop Med Int Health 1999, 4:557-564.

39. Hii JL, Smith T, Vounatsou P, Alexander N, Mai A, Ibam E, Alpers MP: Area effects of bednet use in a malaria-endemic area in Papua New Guinea. Trans R Soc Trop Med Hyg 200I, 95:7-I3.

40. Gimnig JE, Vulule JM, Lo TQ, Kamau L, Kolczak MS, Phillips-Howard PA, Mathenge EM, ter Kuile FO, Nahlen BL, Hightower AW, et al: Impact of permethrin-treated bed nets on entomologic indices in an area of intense year-round malaria transmission. Am J Trop Med Hyg 2003, 68(4 Suppl): I6-22.

4I. Cochrane SH, Leslie J, O'Hara DJ: Parental education and child health: intracountry evidence. Health Policy Educ 1982, 2:213-250.

42. Olaogun AA, Adebayo AA, Ayandiran OE, Olasode OA: Effects of mothers' socio-economic status on the management of febrile conditions in their under five children in a resource limited setting. BMC Int Health Hum Rights 2006, 6:I.

43. Noor AM, Omumbo JA, Amin AA, Zurovac D, Snow RW: Wealth, mother's education and physical access as determinants of retail sector net use in rural Kenya. Malar J 2006, 5:5

44. Bicego GT, Boerma JT: Maternal education and child survival: a comparative study of survey data from 17 countries. Soc $\mathrm{Sc}$ Med 1993, 36: 1207-1227.

45. Wamani H, Tylleskar T, Astrom AN, Tumwine JK, Peterson S: Mothers' education but not fathers' education, household assets or land ownership is the best predictor of child health inequalities in rural Uganda. Int J Equity Health 2004, 3:9.

46. Benet A, Mai A, Bockarie F, Lagog M, Zimmerman PA, Alpers MP, Reeder JC, Bockarie MJ: Polymerase chain reaction diagnosis and the changing pattern of vector ecology and malaria transmission dynamics in Papua New Guinea. Am J Trop Med Hyg 2004, $71: 277-284$.

47. Falk N, Maire N, Sama W, Owusu-Agyei S, Smith T, Beck HP, Felger I: Comparison of PCR-RFLP and Genescan-based genotyping for analyzing infection dynamics of Plasmodium falciparum. Am J Trop Med Hyg 2006, 74:944-950.

48. Cole-Tobian J, Zimmerman PA, King CL: High throughput identification of the predominant malaria parasite clone in complex blood stage infections using a multi-SNP molecular haplotyping assay. Am J Trop Med Hyg 2007, 76:12-19.

49. Karl S, David M, Moore L, Grimberg BT, Michon P, Mueller I, Zborowski M, Zimmerman PA: Enhanced detection of gametocytes by magnetic deposition microscopy predicts higher potential for Plasmodium falciparum transmission. Malar J 2008, 7:66. 